\title{
Deterioration and Conservation
}

\author{
Kirsty High, Kirsty Penkman, Nicky Milner, Steve Boreham, Julie Boreham, \\ Andy Needham, Ian Panter, Margrethe Felter, Becky Knight, Ben Elliott, \\ Michael Bamforth, Maisie Taylor and Charlotte Rowley
}

\section{Introduction}

Deterioration of the deposits at Star Carr became an area of major concern from 2006. Whilst large numbers of lithics were uncovered, organic artefacts were noticeably sparse compared to the previous excavations (Clark 1954; Mellars et al. 1998; Milner et al. 2011), even in the waterlogged parts of the site, which had previously yielded a wide range of organic material. During excavations in 2006 (trench SC22), two clusters of severely compressed worked antler were discovered which had to be excavated on plinths of peat (Figure 22.1). In 2007, in SC24 others were in such advanced states of degradation that they were 'only tentatively identifiable as antler' (Milner et al. 2011, 2823). In 2007, only two certain pieces of bone were found in the wetland trench SC24. One was observed to be spongy in texture, and the other was termed a 'jellybone' having completely lost any mineral content, leaving only the collagen matrix (Milner 2007; Milner et al. 2011). In 2008, a further 'jellybone' was found in SC29 in the field to the north of the Hertford Cut. In the dryland trench SC23 fragments of unidentified bone were found, but all were largely chalky and brittle.

These discoveries were in stark contrast to the remarkable organic remains that had been uncovered in Clark's (1954) excavation. Although robust data regarding the preservation of organic remains from the 1949-1951 excavations is lacking, the robustness of the museum collections, and the sheer abundance of organic artefacts found, suggests that across the majority of the excavated area, conditions were largely conducive to organic preservation (Clark 1954). Similarly, based on excavations by the Vale of Pickering Research Trust during the 1980s (Mellars and Dark 1998), the wealth of organic archaeological and environmental evidence suggests that even delicate plant remains were still reasonably well preserved across the Star Carr site.

In addition to the disparity in the preservation quality of organic materials between excavations, a number of unusual features were identified by excavators, which provided further evidence of localised environmental changes around the site (Needham 2007). Orange residues forming in the flotation tank in 2007 (used to sieve the excavated sediments for small finds) were characterised by their colour as iron oxide, indicative of reactive sediments (Schwertmann and Cornell 2000; Needham 2007). Similar residues had been identified by excavators in and around the site, often appearing to develop within the sediments following exposure to air.

\section{How to cite this book chapter:}

High, K., Penkman, K., Milner, N., Boreham, S., Boreham, J., Needham, A., Panter, I., Felter, M., Knight, B., Elliott, B., Bamforth, M., Taylor, M. and Rowley, C. 2018. Deterioration and Conservation. In: Milner, N., Conneller, C. and Taylor, B. (eds.) Star Carr Volume 2: Studies in Technology, Subsistence and Environment, pp. 175-195. York: White Rose University Press. DOI: https://doi.org/10.22599/book2.h. Licence: CC BY-NC 4.0 

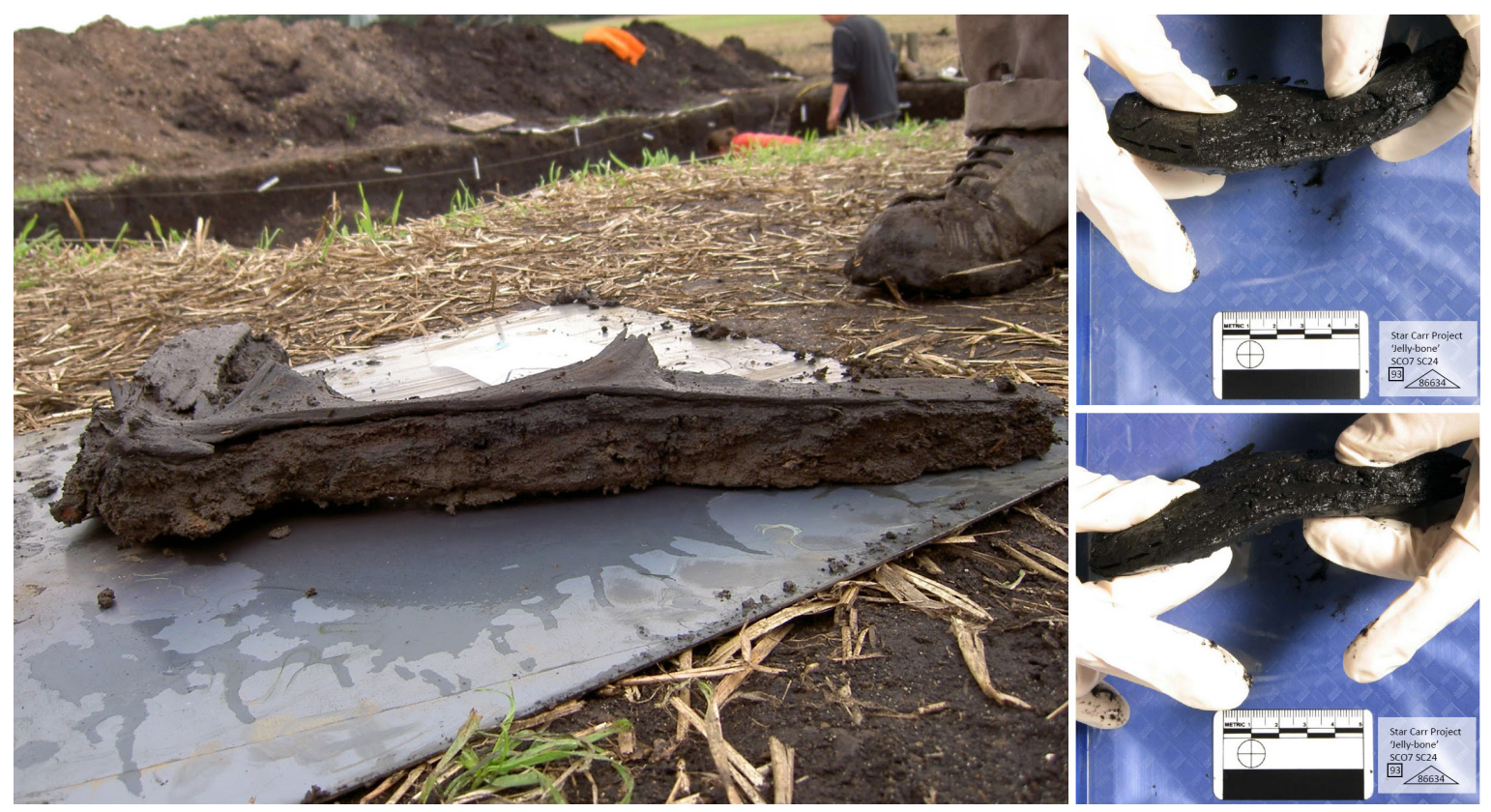

Figure 22.1: Artefacts excavated in 2006 and 2007: (left) flattened antler from trench SC22, lifted on a plinth of peat; (right) 'jellybone' from trench SC24, displaying alarming flexibility (Reprinted from Milner et al. 2011. Copyright (2011) with permission from Elsevier).

Evidence for the peat having shrunk was first observed during excavations in 1985 and 1989 (Mellars and Dark 1998). Between 2004 and 2005, further concerns were raised following field walking and test pitting, during which time it was noticed that the previously invisible slope to the lake edge could now be observed (Milner et al. 2011). Finally, photographic comparison between the re-excavation of Clarks' cutting II trench in 2010 and photographs from the original excavations provided convincing documentation of the extent of peat shrinkage (High et al. 2016b). Based on wider knowledge of waterlogged environments, it was proposed that this shrinkage was almost certainly due to localised land drainage (e.g. Schwarzel et al. 2002; Bain et al. 2011).

These observations have resulted in the instigation of several studies, undertaken both on site and on the artefacts themselves, with the aims of understanding why these changes may have happened, what timescales are likely to have been involved and what effect these changes might have on any remaining archaeology. An initial geochemical survey was carried out by Andy Needham in 2007, followed by a large-scale, English Heritage/Historic England funded geochemical assessment of the site in 2008 and 2010, published by Boreham et al. (2011a; 2011b). English Heritage/Historic England also funded a hydrological investigation, undertaken by Tony Brown and colleagues (Bradley et al. 2012; Brown et al. 2013). Analyses of the organic remains in 2007-9, reported in Milner et al. (2011) was followed by a four-year Natural Environment Research Council (NERC) collaborative PhD project by Kirsty High at the University of York with York Archaeological Trust, which linked the deterioration of the organics with the geochemistry of the site (Brown et al. 2013; High et al. 2015; High et al. 2016a).

The majority of the results from these studies have been published in scientific journals and theses (Needham 2007; Boreham et al. 2011a; Boreham et al. 2011b; Brown et al. 2013; Milner et al. 2011; High 2014; High et al. 2015; 2016a; 2016b; in press); the intention of this review is to bring these studies together and set out an overview of the outcomes of this research, as it relates to many of the materials studied in the following chapters. In addition, it is now possible to map the conditions of the bone, antler and wood against the site conditions in order to correlate site conditions with artefact deterioration. Finally, this chapter sets out the issues faced in conservation of the artefacts and ecofacts. 


\section{Sediment deterioration}

\section{Geochemical changes}

In 2007, pH values recorded during excavations at Star Carr were found to be lower than $\mathrm{pH} 3$ in the southern end of wetland trench SC24 (Needham 2007). This led to the hypothesis that the poor preservation observed in the organic material from the 2006 and 2007 excavations was likely to be linked to geochemical changes, primarily this high acidity. An extensive survey was carried out aimed to build upon this initial evidence, and ascertain the extent of the potential acidification (Boreham et al. 2011a; Boreham et al. 2011b). The survey involved analysis of a series of cores, encompassing three transects across the site at $2 \mathrm{~m}$ resolution. Two of these cut through previous trenches with the aim of establishing any influence of excavation on the chemistry of the sediments.

The sequences were measured for $\mathrm{pH}$ and redox at $0.1 \mathrm{~m}$ depth intervals. The $\mathrm{pH}$ of sediments analysed in the field differed hugely, spanning between $\mathrm{pH}<2$ and 8.43. Sediments also tended to become more acidic with depth, with the region of the archaeology displaying some of the lowest $\mathrm{pH}$ values (Figure 22.2), whilst below the archaeology, $\mathrm{pH}$ tended to rise again. Identical analysis was carried out on archived auger cores (removed during excavations in 1985 and stored at the University of Cambridge in the intervening years), where similar variability in $\mathrm{pH}$ was observed.

The survey also examined the underlying geology of the site, correlating this with the geochemical data. Most significantly, pyrite-rich Speeton or Kimmeridge clay outcrops of varying thickness lie between the peat and the alluvium gravels in places, and these appeared to correlate with areas of increased acidity (Figure 22.2). In contrast, where the peat is underlain by thick gravel rather than clay, $\mathrm{pH}$ tended to be higher. Closer to the lake edge, an increase in $\mathrm{pH}$ was also observed, attributed to carbonate-rich lake marls contributing to a buffering effect (Boreham et al. 2011b). This correlated with the recovery of better preserved organic artefacts, for example, in and around the re-excavation of Clark's cutting II in 2010 (Milner 2010).

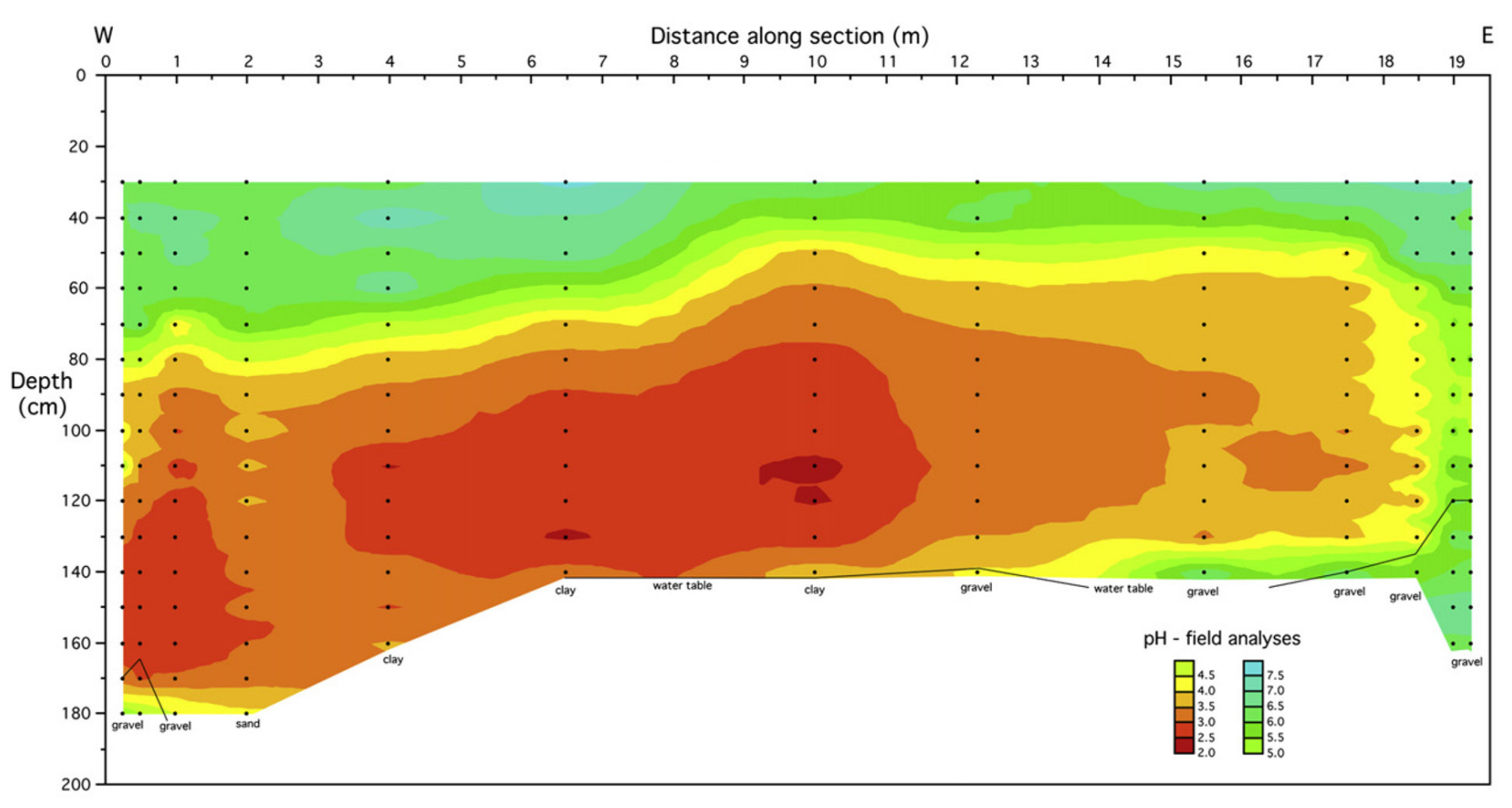

Figure 22.2: $\mathrm{pH}$ measurement recorded across transect 2 (Boreham et al. 2011b). This transect ran from trench VP85A in the east to trench SC24 in the west. The spatial variability is significant and appears to correlate with differences in the underlying geology. Image adapted from Boreham et al. (2011b) (Reprinted from Milner et al. 2011. Copyright (2011) with permission from Elsevier). 
The concentrations of sulfur were also found to be elevated throughout each transect. High concentrations were often associated with elevated iron concentrations, leading to the hypothesis that both originated from pyrite $\left(\mathrm{FeS}_{2}\right)$ in the underlying clay deposits (Boreham et al. 2011b). In addition, sulfur concentrations tended to be higher towards the base of the sequences, indicating that the source of the sulfur was from below the sequence. These observations, along with high sediment sulfate: sulfide ratios, provided significant evidence to suggest that the high acidity at Star Carr is the result of the dissolution and subsequent oxidation of iron sulfides to sulfate, eventually leading to the formation of sulfuric acid (Equation 1).

$$
\mathrm{FeS}_{2(\mathrm{~s})}+3 \mathrm{O}_{2(\mathrm{~g})}+2 \mathrm{H}_{2} \mathrm{O}_{(\mathrm{l})} \longrightarrow \mathrm{Fe}^{2+}+2 \mathrm{SO}_{4}{ }^{2-}+4 \mathrm{H}^{+} \quad \text { Equation } 1
$$

Other tests seemed to confirm this hypothesis. Time-dependent analysis, where $\mathrm{pH}$ measurements were taken at intervals of several minutes following exposure to air, showed that in samples already displaying acidity, $\mathrm{pH}$ decreased logarithmically, demonstrating a tendency to undergo oxidation rapidly upon exposure to air (e.g. Patrick and Mahaptra 1968). Changes in redox potential, as well as iron II: iron III ratios between the field and lab, further confirmed the vulnerability to oxidation displayed by the sediments at Star Carr.

Of greater concern was the observation that where the auger survey transected through previously excavated trenches, some evidence for a 'halo' effect was observed; $\mathrm{pH}$ was increased in the backfill and extended horizontally into fresh sediments, compared to the surrounding sediment. This may also explain the better preservation in Clark's cutting II in 2010, and provided the first indication that excavation of the site may itself modify the burial environment.

In 2013, a smaller-scale investigation was carried out during archaeological excavations (High 2014). Rather than provide new data, the aim of these analyses was to test the observations from the 2009 study and establish whether the extremes in geochemistry reported in 2007 and 2011 were permanent.

In the 2013 study, redox potential and $\mathrm{pH}$ measurements were recorded across the surface of the excavated trench in association with organic finds, and as such were opportunistic rather than systematic. However, the analysis clearly confirmed the vast spatial (horizontal and vertical) variation across the site, with the lowest $\mathrm{pH}$ measured nearest the archaeology (assessed by measuring every $0.1 \mathrm{~m}$ down the trench wall). Changes in $\mathrm{pH}$ following exposure were again evident, similar to the time-dependent study reported by Boreham et al. (2011b).

$\mathrm{pH}$ values ranged from almost neutral to less than 2 (Figure 22.3), with elevated ( $>400 \mathrm{mV}$ ) redox measurements in parts of the site confirming the reactivity of the sediments. Samples taken close to the backfill of previously excavated trench VP85A were much less acidic than those in a newly excavated trench. An explanation for this could be that neutralised topsoil was mixed into the peat during backfilling in 1985, further supporting the proposal by Boreham et al. (2011b) that excavation of the site may significantly alter the burial environment. In 2016, a supplementary pH measurement was taken on a bulk soil sample (S3599) taken from Clark's baulk, underneath the faunal remains. The $\mathrm{pH}$ of this sample was measured as 3.93 at $24.5^{\circ} \mathrm{C}$.

As part of the 2013 study, elemental analysis (carbon, nitrogen, sulfur and hydrogen content) was carried out on several samples using a Thermo Flash 2000 Elemental Analyser (see High 2014). Sulfur content ranged from $1.4-20 \%$, again with high levels of spatial variability. As soils typically range from $0.005-0.05 \%$ sulfur content (Steinbergs et al. 1962), this confirms that levels of sulfur across the site are extremely elevated, as first reported by Boreham et al. (2011a; 2011b). Minimal correlation is seen between $\mathrm{pH}$ and sulfur content, although there did seem to be a lower level of carbon present in samples with a higher $\mathrm{pH}$. This could suggest that a higher clay content (characterised by a lower carbon content) leads to increased buffering of any acidity (e.g. Dypvik 1984).

\section{Hydrological changes}

Following the geochemical survey, it became clear that the most likely cause of site acidification was the formation of sulfuric acid via sulfide oxidation (Equation 1). The most likely cause of this was considered to be a loss of waterlogging at the site, leading to the introduction of air into the previously saturated (and therefore geochemically stable) sediments. The evidence for loss of waterlogging at Star Carr was already clear; the peat shrinkage and a distinct lack of water in the excavated trenches when compared to early excavations, indicated that the site was not always permanently saturated.

To provide conclusive data affirming this loss of waterlogging, as well as determining whether this was a permanent or seasonal, recent or historic scenario, hydrological assessment of the area surrounding Star 


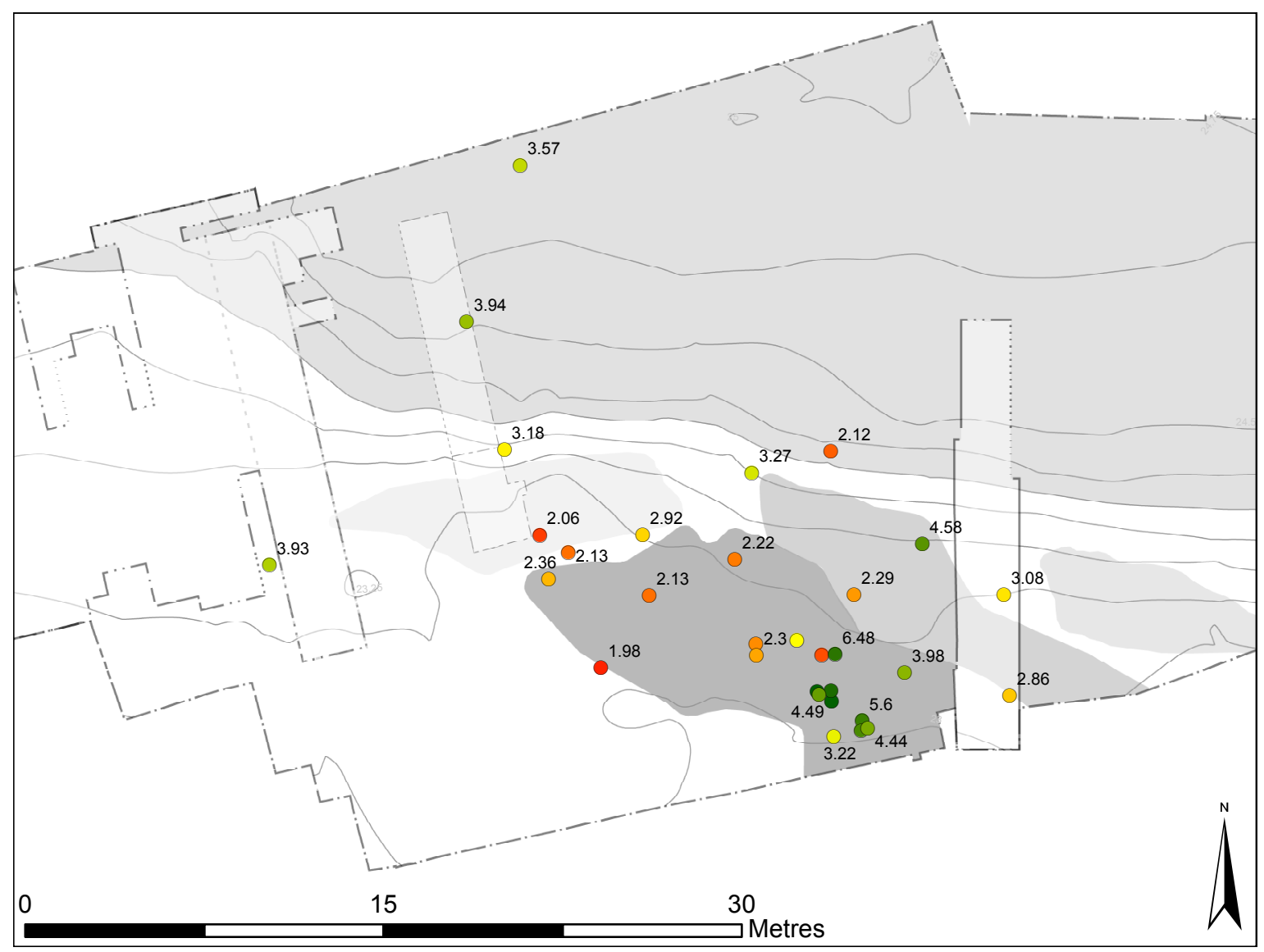

Figure 22.3: Plot of $\mathrm{pH}$ values measured in 2013 by $\mathrm{KH}$ across the surface of SC34 (with some $\mathrm{pH}$ values labelled for reference), including the 2016 reading from Clark's baulk. Values ranged from pH 6.58 (darkest green) to 1.98 (darkest red) (Copyright Star Carr Project, CC BY-NC 4.0).

Carr was undertaken. The first study, carried out by the University of Southampton, aimed to determine the source of groundwater at the site and infer the effects that drainage may be having on the land (Brown et al. 2013). This was undertaken using computer modelling as well as by collating existing hydrological data from the British Atmospheric Data Centre, the Environment Agency and the British Geological Survey. These data indicated that the insertion of an underground drainage system in the year 2000 may have lowered the water table by as much as $0.5 \mathrm{~m}$, and as such resulted in the Star Carr site effectively being isolated from any regional hydrological influences. Measurements of water levels in a series of dip-wells between September 2010 and September 2011 confirmed these findings, further suggesting that recent drainage at the Star Carr site had occurred, and was the result of field drainage rather than wider hydrological influences (Bradley et al. 2012).

Isotopic analysis of hydrogen and oxygen present in groundwater can be used to identify the source of the groundwater, as processes occurring during the water cycle cause the relative proportions of heavy and light isotopes to alter (Bradley et al. 2007). Isotopic analysis was therefore carried out during both studies, on water samples taken from the dip-wells, the nearby Hertford cut, the bordering field ditches and a nearby chalk spring that is understood to originate directly from a local limestone aquifer underlying the Star Carr site. Results from this analysis suggested that the groundwater is likely to originate from precipitation, rather than any local aquifers, thus further confirming the hydrological isolation of the Star Carr site and the hypothesis that the insertion of the field drains was the primary cause of loss of waterlogging at the site. 


\section{The current understanding of geochemical and hydrological conditions}

The geochemical and hydrological investigation summarised here have provided significant evidence that the Star Carr site permanently contains localised regions of incredibly high acidity. However, less acidic areas do exist, particularly where the presence of marl appears to have caused a buffering effect, or in proximity to previous excavations where a halo effect has increased the $\mathrm{pH}$. High redox values and rapid further acidification upon exposure indicate that the sediments are highly vulnerable and reactive, meaning that the site is likely to be at risk from continued acidification, resulting in an even lower $\mathrm{pH}$ than already recorded in parts of the site.

High levels of sulfur and iron have led to the hypothesis that acidification has been caused by the solubilisation of pyrite originating from the underlying Speeton and Kimmeridge clay deposits (Boreham et al. 2011b). When exposed to oxygen (i.e. by loss of waterlogging), sulfuric acid is formed, in a process similar to acid rock drainage (Equation 1).

Although agricultural activities such as fertilisation may also have some contribution (Needham 2007), hydrogen and oxygen isotope analysis and the pattern of sulfate concentrations in the sediments suggest that the source of the sulfur lies primarily below the archaeology (Boreham et al. 2011a; Boreham et al. 2011b; Brown et al. 2013). The hydrological isolation of the site (Brown et al. 2013) also suggests that the source of sulfur is likely to be from the geology, rather than external factors such as the nearby landfill site. The spatial variations in $\mathrm{pH}$ and redox potential across the Star Carr site are more difficult to interpret; regions of high acidity lie in close proximity to almost neutral sediments. Boreham et al. (2011a) discuss the role played by differences in the sediments directly underlying the peat deposits in causing these inconsistencies. Areas of lake marl near the lake edge appear to have caused a buffering effect. In addition, lower $\mathrm{pH}$ where thin layers of clay lie between the peat and the gravelly bedrock could be explained by restricted movement of the water table; this means that when the water levels drop below the level of the archaeology, they take longer to rise again, resulting in greater oxidation of sulfides. Boreham et al. (2011a) suggest that if the water table was constantly above this clay lens, the effects would be benign or even beneficial. A lowered water table therefore appears to be the most significant event, instigating the formation of sulfuric acid in the archaeological horizon at Star Carr, and has been attributed to the insertion of field drains in the year 2000 (Brown et al. 2013). An additional consequence of this loss of waterlogging is the severe peat shrinkage observable across the site. This is likely to be a completely irreversible change (Schwarzel et al. 2002).

\section{Material deterioration}

\section{Scope of study}

A number of other examples have previously demonstrated the severity by which altered water tables can affect organic archaeology. These include Flag Fen, where documented peat shrinkage has affected the Bronze Age timbers left in situ (Pryor 1991) and Fiskerton, where drainage of the site was observed to result in the almost complete loss of archaeological bone (Williams et al. 2006). However, the $\mathrm{pH}$ reported at Star Carr presents a uniquely harsh burial environment; experimental studies rarely consider $\mathrm{pH}$ as low as at Star Carr, and as such an understanding of organic preservation under these conditions is limited, although it would be reasonable to expect conditions to have a detrimental effect. In particular, at low $\mathrm{pH}$ previous studies have indicated that hydroxyapatite in bone is vulnerable to dissolution, and the cellulose in wood to acid hydrolysis (e.g. Gordon and Buikstra 1981; Fengel and Wegener 1984).

A great deal of the recent diagenesis research at Star Carr has focused attention on the state of preservation of the organic remains excavated (bone, antler and wood). This has ranged from visual assessment (Milner 2007) to the more in-depth chemical analysis (Milner et al. 2011).

The results from this initial assessment initiated a wider study carried out by KH in which the organic deterioration was related to the geochemistry of the site. In addition, work was undertaken by the bone, antler and wood specialists to score levels of deterioration and information potential. As there was no direct correlation between these two types of observation, and the assessment of the condition of the assemblage could not be carried out in a conventional manner, a tailor-made scoring system was created by RK, BE and MB. For exam-

ple, a highly demineralised specimen while being considered poorly preserved may still hold the potential to 
allow species and element to be established, and even in some cases, for the identification of modifications such as butchery evidence.

\section{Bone and antler}

Assessment of bone and antler preservation carried out during excavations in the 1950s and 1980s was limited to visual analysis. Clark $(1954,7)$ described the majority of both bone and antler as robust and firm. However, some pieces, such as the barbed points, found on what would have been dryland were described as 'dark in colour and soft as leather' (Clark 1954, 1). Excavations in 1985 and 1989 uncovered a large array of well-preserved faunal material, although a number of fragments of bone were assessed to be in a poor state of preservation (Rowley-Conwy 1998), but further detail was not reported.

In 2009, metrical analysis was carried out on antler recovered from all three phases of excavation (Milner et al. 2011). Results showed that whilst antler excavated by Clark had largely preserved its original shape and texture, antler excavated in the 1980s (Mellars and Dark 1998) was visibly more flattened, and those from the most recent excavations even more so. This was taken as further evidence that peat shrinkage had occurred, possibly resulting in compression, or flattening, of the organic remains.

Two 'jellybone' samples were discovered in 2007 and 2008 (Milner et al. 2011), both in areas of the site with very low recorded $\mathrm{pH}$ (between 2.5-3 and approximately 3.4 respectively; Boreham et al. 2011b). Analysis of the two 'jellybones' was carried out shortly after excavation (Milner et al. 2011). Histological integrity was determined by optical microscopy and transmission electron microscopy (TEM), showing that both bones were almost completely demineralised, with elevated total amino acid concentrations further confirming the extent of this demineralisation. However, the low levels of amino acid racemisation (employed as a measure of collagen damage) indicated that deterioration may either have occurred very rapidly, or that any deteriorated collagen had leached out of the bone, reducing the observed racemisation.

In 2010, significant quantities of faunal remains were uncovered in the backfill of Clark's cutting II (Chapter 7). Although an initial assessment determined these to be reasonably well-preserved, some deterioration was visible several weeks following excavation. These observations include longitudinal splitting of rib bones due to rapid formation of crystals within the structure, and the formation of orange deposits on the surface of larger bones (determined to be iron-based) (Figure 22.4). Similarly, in 2013 a few examples were identified where a hard, cement-like layer was found adhered to the cortical bone surface shortly after excavation. Chemical analysis of this material has revealed it to be a mixture of hydroxyapatite (excreted from the degrading bone) and fragments of the surrounding sediments which adhere and then harden. In other bones, demineralisation also appeared to have occurred post-excavation, with the development of 'jelly-like' areas in the bones (Figure 22.5).

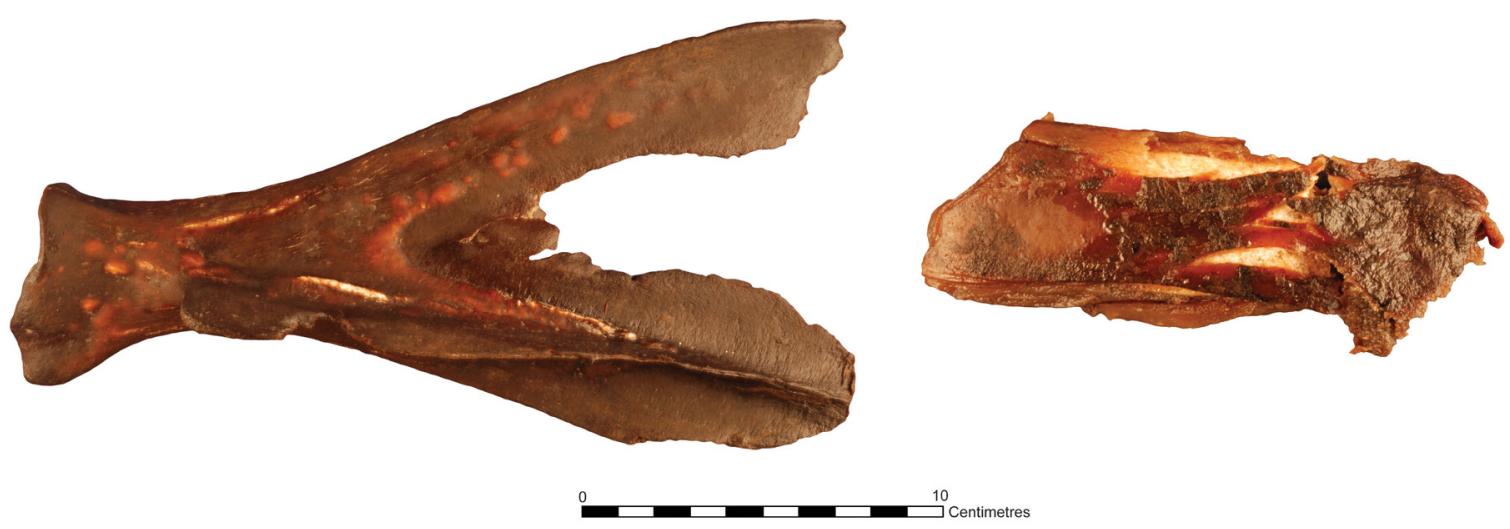

Figure 22.4: Examples of bone with crystals creating 'bubbles' under the cortical bone (left) and pushing completely through the cortical bone (right) (Copyright Becky Knight, CC BY-NC 4.0). 

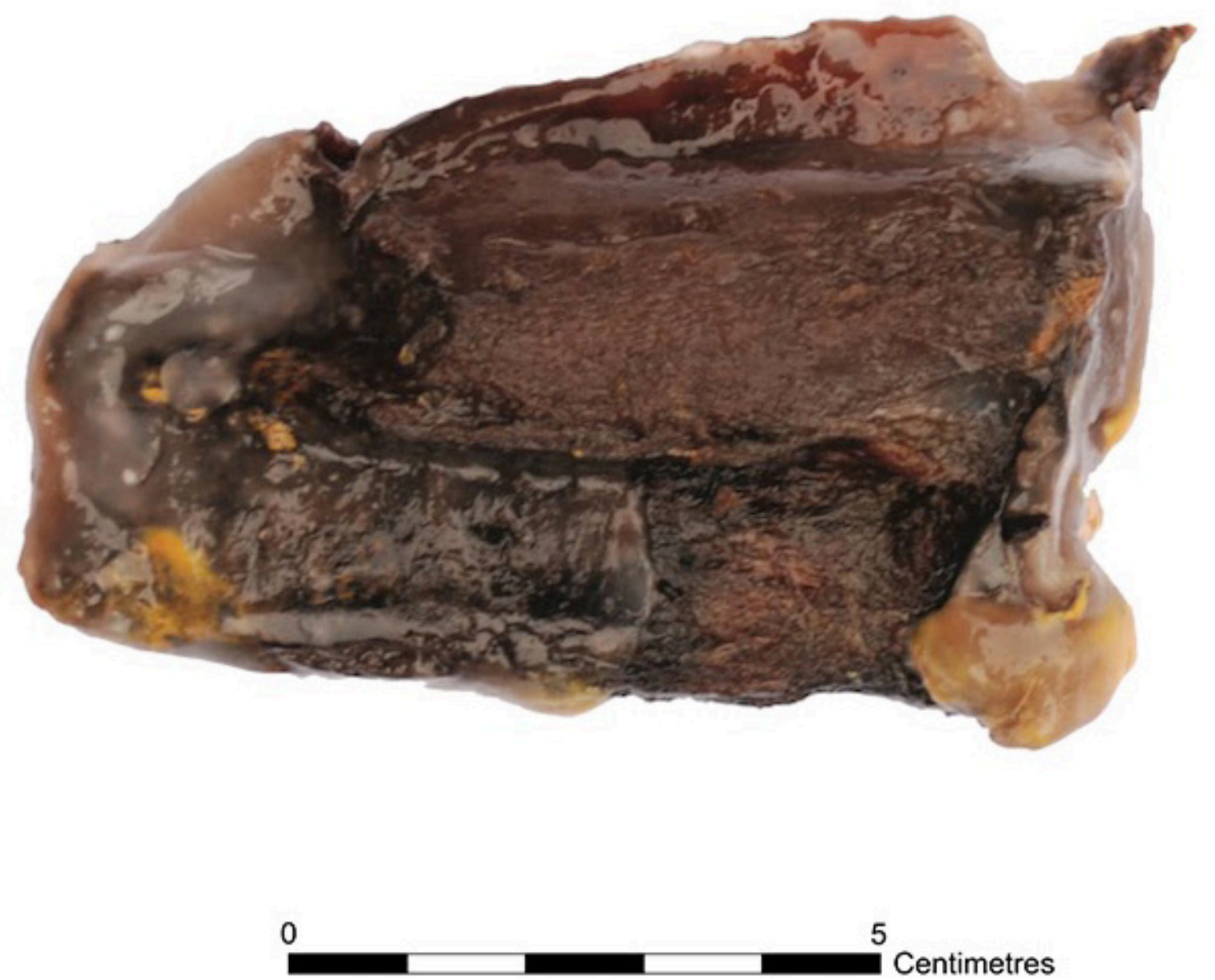

Figure 22.5: An example of a bone which shows severe deterioration in the form of collagen excretions (Copyright Michael Bamforth, CC BY-NC 4.0).

Further chemical analysis of selected samples of bone revealed substantial differences in bone preservation across the site, again reflecting the differences in site geochemistry (High et al. 2016b). Analysis of both the amino acid content and bone mineral of several samples recently excavated from Star Carr has shown primarily that bone from the dryland areas of Star Carr contain very little collagen, yet hydroxyapatite is still present. Elevated aspartic acid racemisation indicated that what little collagen remains is highly degraded.

In contrast, the discovery of large numbers of 'jellybones' during the 2013 excavation season, which contain almost no hydroxyapatite, suggest an alternative mode of deterioration in the wetland areas of the site. The low levels of aspartic acid racemisation suggest either that degraded fragments of collagen are quickly leached away or that loss of hydroxyapatite has occurred so recently that collagen breakdown has not yet had chance to occur (High et al. in press). This supports the results obtained in 2007-8, leading to the conclusion that some bones are literally being washed away, making it unlikely that bone in that state of preservation would survive in situ for very long. The significant difference in racemisation values across the Star Carr site indicate that localised geochemical conditions may be causing accelerated deterioration of the bone collagen only in very specific areas.

The chalky deposits which developed on some bones post-excavation, as well as several bones from both the wet and dryland contexts excavated between 2010 and 2013, were analysed using powder X-ray diffraction, to examine the structure of any remaining hydroxyapatite (High et al. 2016b; High et al. in press). The diffraction patterns of the chalky deposits, as well as some bone from the wetland areas indicated an overwhelming presence of gypsum (calcium sulfate) rather than hydroxyapatite (calcium phosphate). Such dramatic alteration of bone mineral has not previously been reported, but is almost certainly the result of such high concentrations 
of sulfur in the burial environment. Currently, the implications of such a transformation are not understood; however, bone mineral is known to play a vital role in protecting bone collagen (e.g. Collins et al. 2002; Hedges 2002), suggesting a significantly detrimental effect on the state of preservation of the organic remains.

Composed of mineralised collagen, antler is likely to undergo similar degradation mechanisms to bone. However, the lower degree of mineralisation may make it more vulnerable to acidification (e.g. O'Connor 1987). During excavations in 2013, further evidence for antler deterioration was uncovered. Several pieces were identified as too degraded to remove intact, and several displayed a jelly-like texture, indicative of loss of hydroxyapatite (demineralisation). Although much of the antler was described as in generally reasonable condition, flattening (presumably due to peat compression) was again a major problem and led to a limitation on the quality of archaeological information that could be ascertained. However, the variability in the quality of the antler was of particular note; these variations are probably a reflection of the variations in the geochemistry of the site. Whilst in some instances the worked surfaces were excavated intact, allowing a full traceological analysis of the piece (Chapter 24), in other instances demineralisation has destroyed the surface details.

Each faunal specimen has been rated first for its preservation and then for its information potential based on a series of categories (Tables 22.1 and 22.2). Due to the complicated nature of the preservation issues, in some cases more than one of the nine preservation categories was applied to a single specimen. For information potential, each individual specimen was scored from 1-5. These scores are logged on the faunal spreadsheet which is archived in ADS.

Figures 22.6 and 22.7 display plots of the bone and antler artefacts across site, colour-coded by their robustness and information potential respectively. As can be seen for robustness, the most robust artefacts are found

\begin{tabular}{|l|l|}
\hline Preservation Category & Definition \\
\hline A & Material is robust and intact \\
\hline B & Material is intact but fragile \\
\hline C & Material is partially fragmented \\
\hline D & High fragmentation \\
\hline E & \\
\hline F & Material is compressed and misshapen \\
\hline G & $\begin{array}{l}\text { Leaching white mineral excretion and/or pooling to form cysts under the cortical bone, but } \\
\text { not delaminating }\end{array}$ \\
\hline H & Delamination of the cortical bone and mineral eruptions (including milky white excretion) \\
\hline I & Partial demineralisation with varying patches of robust and soft bone \\
\hline
\end{tabular}

Table 22.1: Preservation scoring system. Categories E-I represent the extreme range of conditions which are specific to Star Carr.

\begin{tabular}{|l|l|}
\hline $\begin{array}{l}\text { Information } \\
\text { Potential }\end{array}$ & Definition \\
\hline $\mathbf{1}$ & $\begin{array}{l}\text { Highly fragmented or complete lack of identifiable surfaces/characteristics; result is the inability to } \\
\text { identify the specimen at all }\end{array}$ \\
\hline $\mathbf{2}$ & Fragmentation/compression only allows broad species/element categories to be identified \\
\hline $\mathbf{3}$ & Only the general shape and structure survives to allow for identification to be established \\
\hline $\mathbf{4}$ & Majority of characteristics are available to allow identification but there is a small amount of damage \\
\hline $\mathbf{5}$ & $\begin{array}{l}\text { Material is pristine; looks like modern bone; the specimen is easily identifiable and it is possible to } \\
\text { yield a complete analysis }\end{array}$ \\
\hline
\end{tabular}

Table 22.2: Information potential scoring system. 


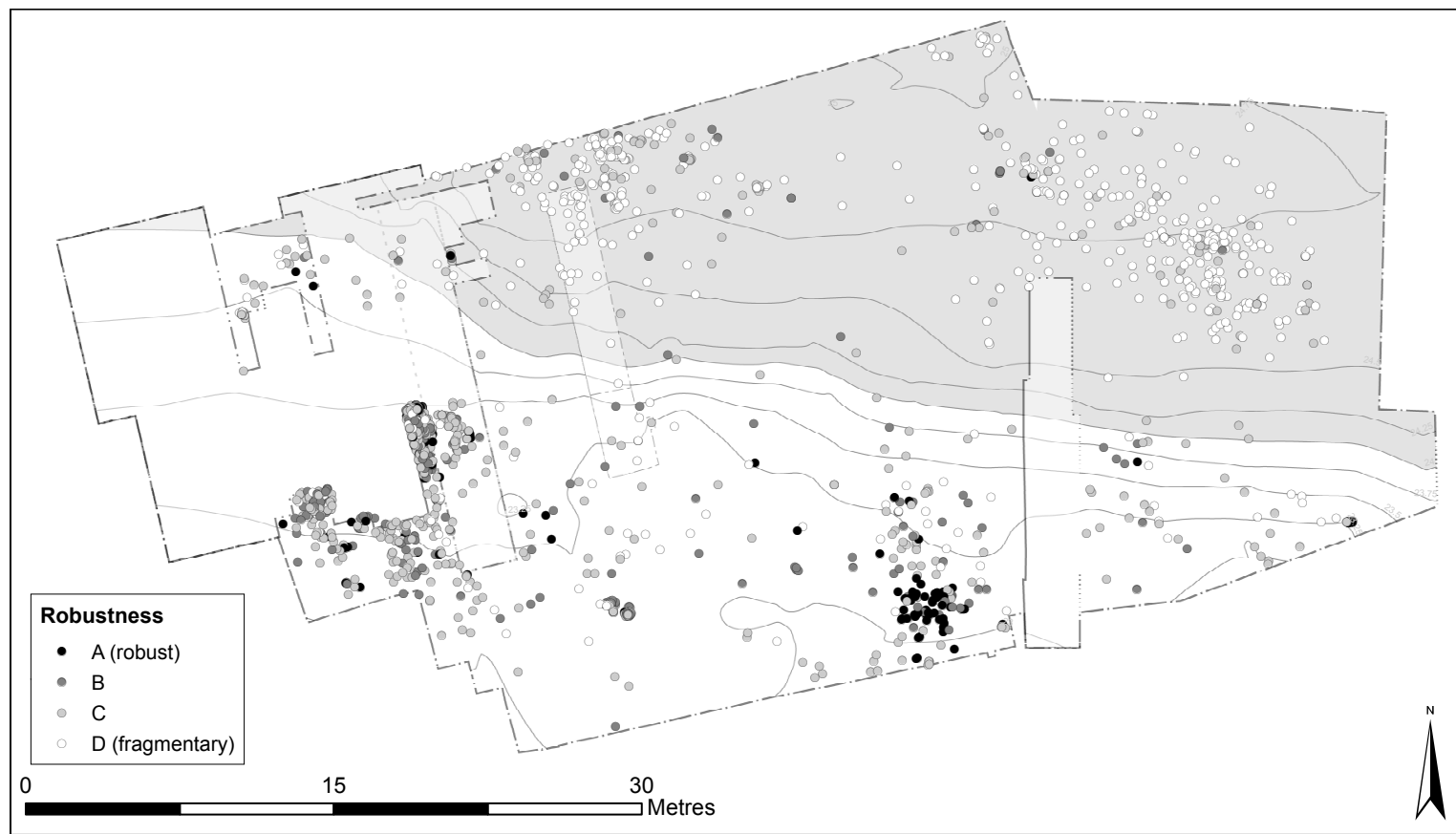

Figure 22.6: Plot of all bone and antler artefacts rated by robustness from robust (black, rating A) to fragmentary (white, rating D) (Copyright Star Carr Project, CC BY-NC 4.0).

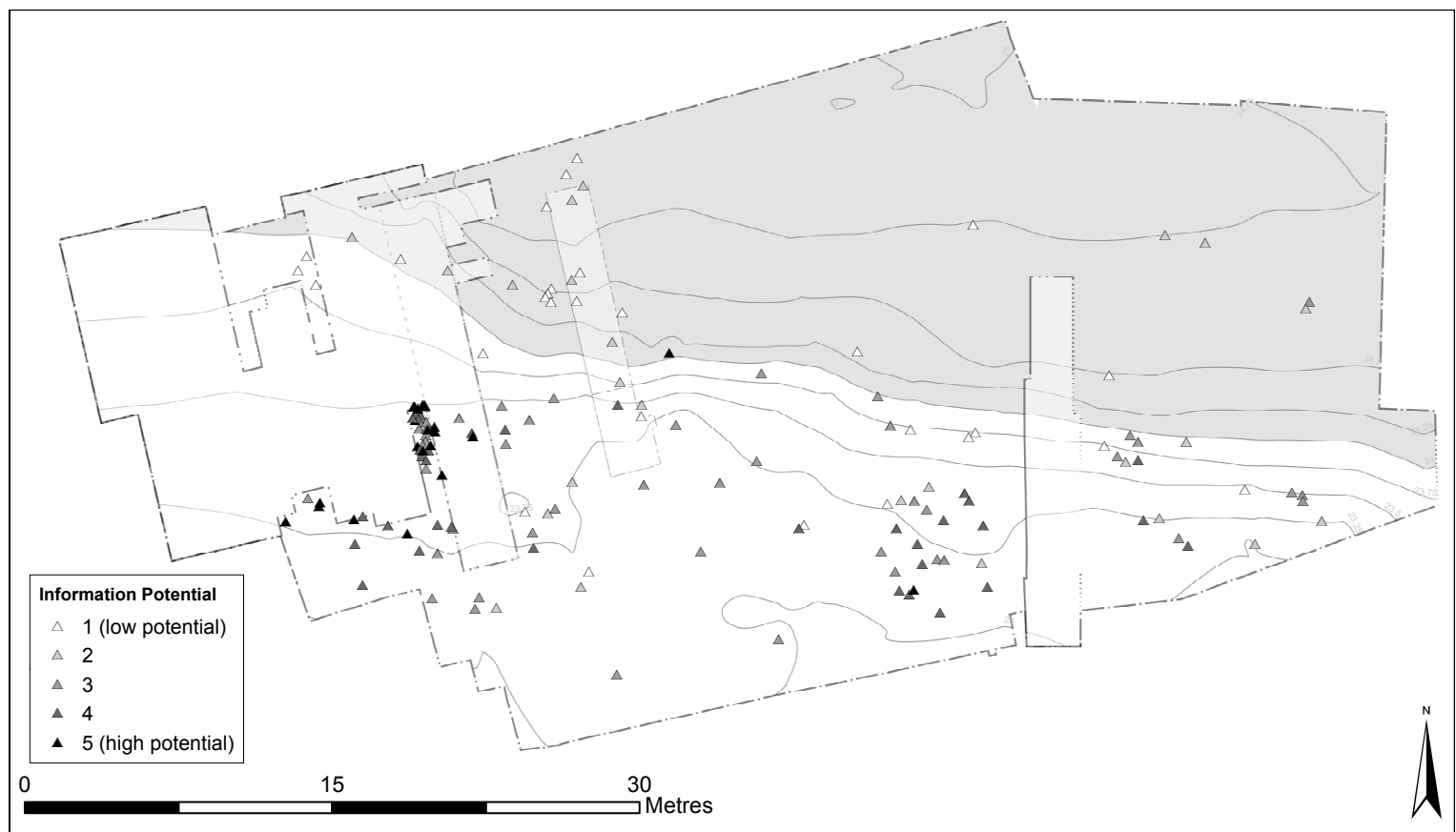

Figure 22.7: Plot of all bone and antler artefacts rated by information potential from excellent (black, rating 5) to poor (white, rating 1) (Copyright Star Carr Project, CC BY-NC 4.0). 


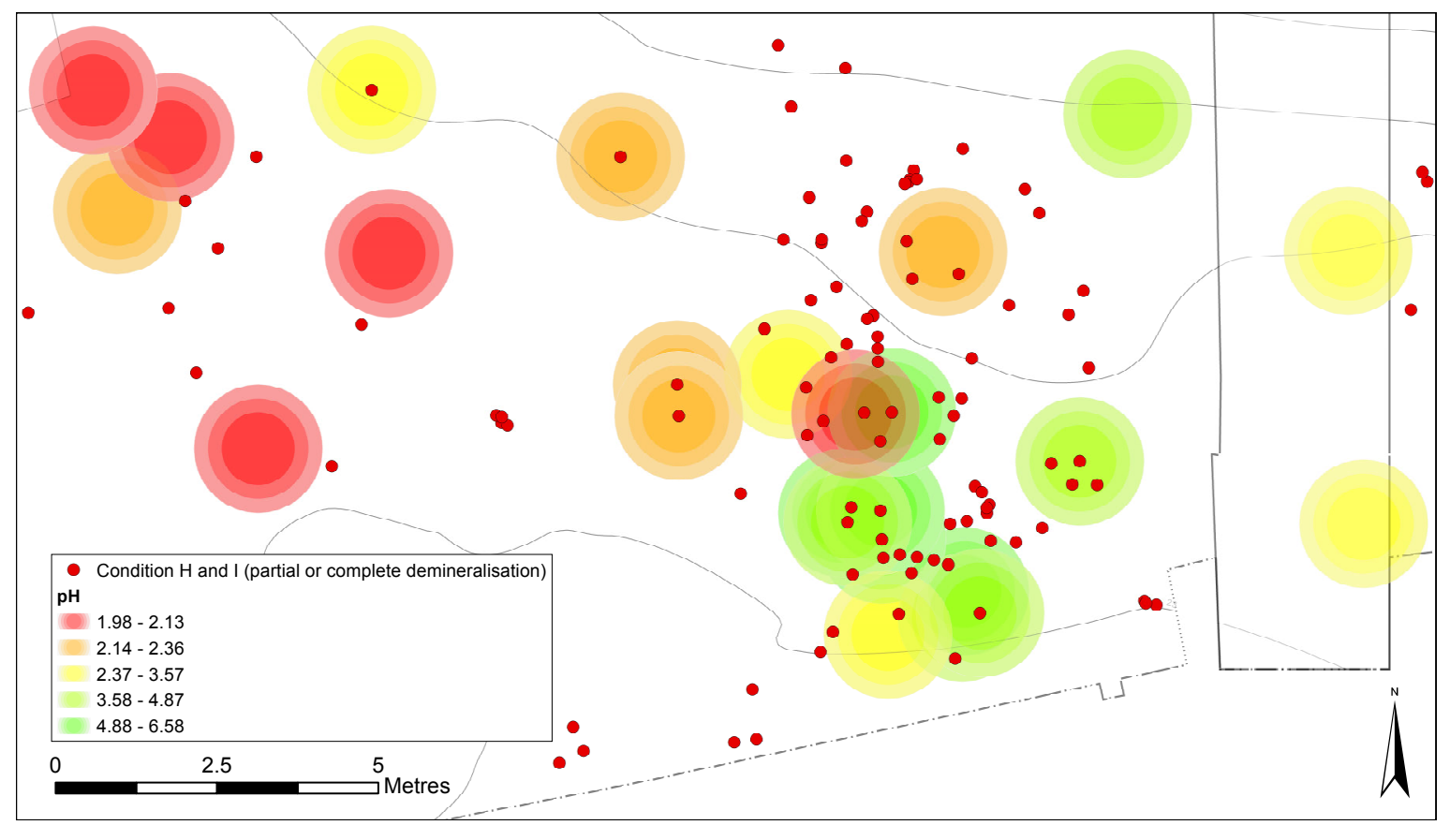

Figure 22.8: The $\mathrm{pH}$ values around the detrital wood scatter together with partially or completely demineralised bone and antler artefacts (Copyright Star Carr Project, CC BY-NC 4.0).

in the wetland, particularly in Clark's area and also the cluster around the detrital wood scatter, to the west of trench VP85A, an area of neutral $\mathrm{pH}$ readings. The information potential ratings produce a fairly similar pattern with the highest potential in the areas of better preservation. Further examination of the area around the detrital wood scatter, where robustness and information potential is favourable, shows that even in this area, with less acidic conditions, partial or complete demineralisation has occurred (Figure 22.8). It is therefore important not to assume that less acidic areas will be safer from these issues.

Overall, the best preservation found on the site was in Clark's area in 2015, from within the section of baulk. This contained a tightly packed accumulation of wood, bone and antler that was much more robust than in other areas of the site, and which appeared to be similar in condition to the material originally excavated by Clark. It would appear that this very small pocket of sediment had been buffered somehow, either by the quantity of bone and antler in this area, and/or by near-neutral backfill (as observed in Clark's cutting II re-excavated in 2010), and the area of marl to the south.

\section{Wood}

Descriptions of wood from the original excavations suggest that it was soft because roots had grown through the artefacts. However, visual records show that it retained the macroscopic appearance of wood (Clark 1954). Images of the excavations in 1985 and 1989 also show the wood to be macroscopically identifiable as wood, although in some instances it was difficult differentiating between the timbers and the surrounding peat matrix (Taylor 1998b). The surface data recorded from these timbers is the clearest fine-grained evidence of woodworking recorded from Star Carr. Wood has never been retrieved from the dryland parts of the site; however this is not surprising, as archaeological wood only usually survives when biological activity has been suppressed, for example by waterlogging (Blanchette et al. 1990; Florian 1990).

Wood excavated in 2006 and 2007 was visually observed to be well preserved but on handling was found to be extremely delicate (Milner et al. 2011), meaning great care had to be taken at all stages of excavation, cleaning and storage to ensure that vital surface data were protected. The peat-wood interface was often very difficult 
to define and as a result wood was difficult to analyse. Where possible, the condition of the wood was further assessed by York Archaeological Trust using scanning electron microscopy (SEM) imaging and standard decay tests such as density and maximum water content ( $\mu$ max) (Milner et al. 2011). This analysis showed that little or no cellulose was remaining in much of the wood, leaving only a lignin-rich skeleton. Again, preservation appeared to vary across the site, although the major damage was concluded to be due to compression, rather than chemical or biological deterioration.

More in-depth analysis in 2013 supported these observations; analysis by FT-IR, gas chromatography and SEM showed that although much of the cellulose within the Star Carr wood was degraded, it was not unusually so. Comparison with samples from Must Farm and Flag Fen (considered examples of exceptionally well-preserved archaeological wood), showed that for a site the age of Star Carr, the wood was still as well-preserved as could be expected. In an archaeological context, this means that information such as primary conversion, species and growth ring data can still be determined and fine-grained surface detail, such as tool facets, are sometimes visible.

The analysis in 2013 aimed to tie in the organic deterioration with the site geochemistry, and this showed some alarming results (High et al. 2016b). Analysis of the surface $\mathrm{pH}$ of many excavated samples showed that upon excavation, the $\mathrm{pH}$ of the wood drastically decreased. Furthermore, a timber that had been excavated in 2007 and kept in storage showed a surface $\mathrm{pH}$ of much less than 1; far lower than has ever been recorded at the site itself. Chemical analysis of this timber revealed extensive degradation, with both the lignin and cellulose completely broken down, likely due to acid hydrolysis (see High et al. 2016b). These observations demonstrate that the influence of the harsh burial environment at Star Carr extends beyond excavation and suggests that drying out of the site will be highly detrimental to the continued survival of any remaining wood. Introduction of oxygen to the wood will lead to increased acidity within the wood structure, making it then vulnerable to chemical modification.

During the 2013-2015 excavations all individually recorded pieces of wood were scored for condition. The condition scale developed by the Humber Wetlands Project was adopted at Star Carr (Table 22.3). The condition scale is based primarily on the clarity of surface data. Material is allocated a score dependent on the types of analyses that can be carried out, given the state of preservation. The condition score reflects the possibility of a given type of analysis but does not take into account the suitability of the item for a given process. If preservation varies within a discrete item, the section that is best preserved is considered when assigning the item a condition score. In addition to the condition score assigned to each item, further information regarding condition, taphonomy and damage was noted on the individual wood sheets as appropriate.

An overview of the assemblage is given in Table 22.4. The most common condition score is a $3 /$ moderate, describing material where the primary conversion is visible, identification to taxa is possible and growth ring data is visible. Fine-grained surface data such as tool facets may be visible. Fine grained surface data is very unlikely to be visible for material that scores less than a 3 , whereas it generally will be visible for material that scores more than a 3. Although preservation was highly variable at an extremely localised level, condition generally improved both as depth and distance from the lake edge increased. This is particularly evident in the areas around the eastern and western platforms; however, condition was again much better in Clark's area even closer to the lake edge (Figure 22.9).

\begin{tabular}{|c|c|c|c|c|c|}
\hline Condition score & $\begin{array}{l}\text { Museum } \\
\text { conservation }\end{array}$ & $\begin{array}{l}\text { Technology } \\
\text { analysis }\end{array}$ & $\begin{array}{l}\text { Woodland } \\
\text { management }\end{array}$ & $\begin{array}{l}\text { Dendro- } \\
\text { chronology }\end{array}$ & $\begin{array}{l}\text { Taxonomic } \\
\text { identification }\end{array}$ \\
\hline 5 excellent & + & + & + & + & + \\
\hline 4 good & - & + & + & + & + \\
\hline 3 moderate & - & $+/-$ & + & + & + \\
\hline 2 poor & - & $+/-$ & $+/-$ & $+/-$ & + \\
\hline 1 very poor & - & - & - & - & $+/-$ \\
\hline 0 non-viable & - & - & - & - & - \\
\hline
\end{tabular}

Table 22.3: Condition scale, after Van de Noort et al. (1995): Table 15.1. 


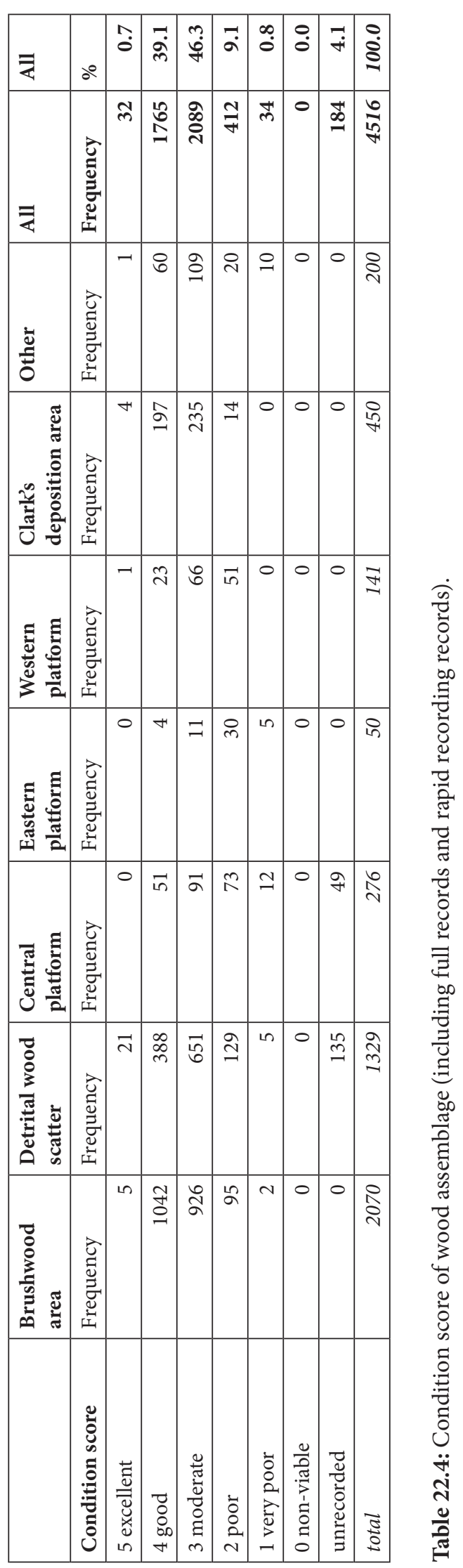




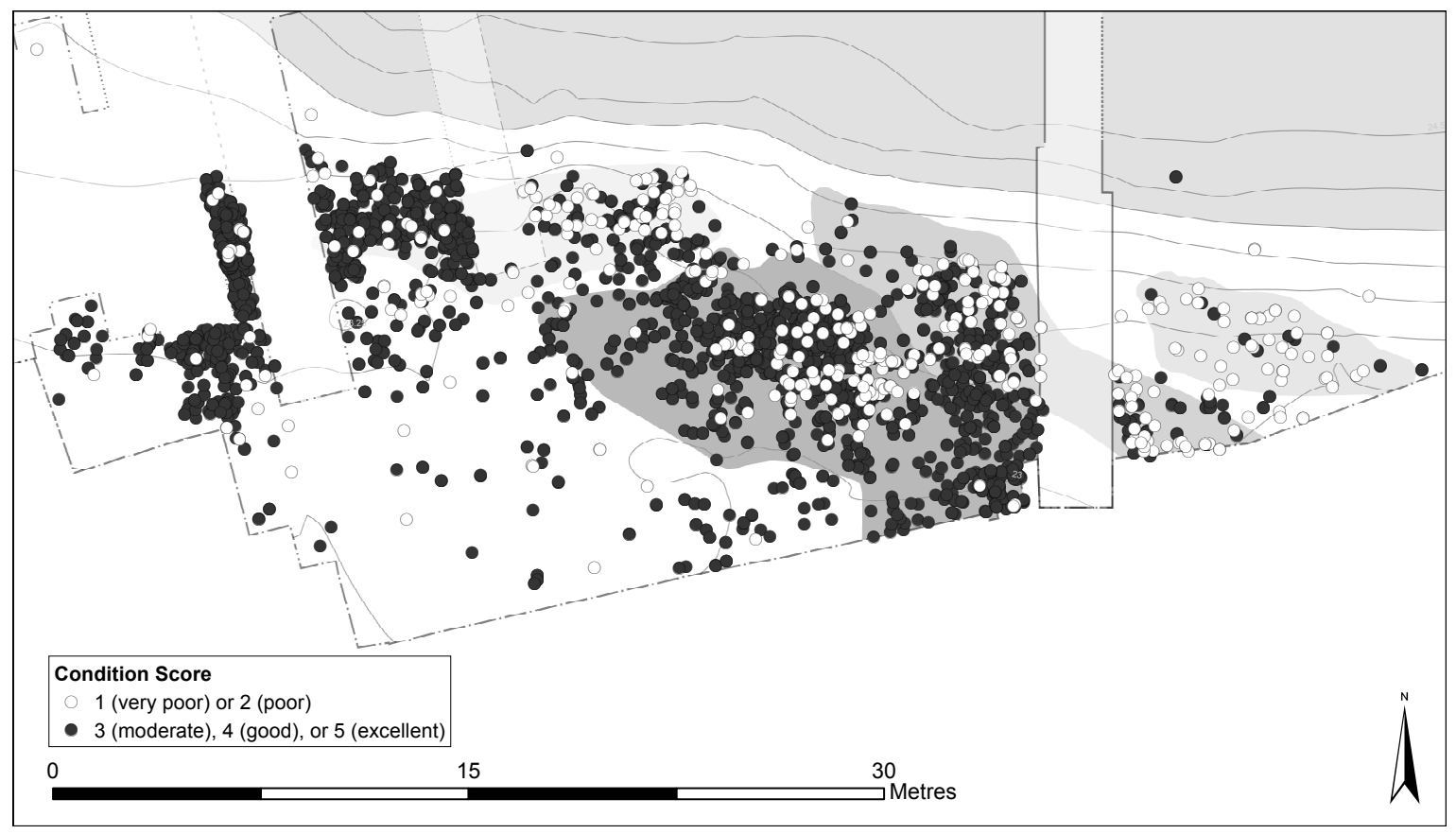

Figure 22.9: Plot of condition score of wood assemblage of pieces rated 3 or greater (moderate, good or excellent) against pieces rated $<3$ (poor or very poor) for wood with survey data (2179 pieces) (Copyright Star Carr Project, CC BY-NC 4.0).

The wood assemblage has been damaged by compression as the site has dewatered and the waterlogged deposits have shrunk in the vertical plane. By measuring the vertical and horizontal diameter of wood that originally had a circular cross section, the degree of vertical compression can be mapped (Figure 22.10). In the most extreme cases, wood has been compressed by $97 \%$. The mean average of compression is $39 \%(\mathrm{~N}=937)$ (Figure 22.11).

Based on the assumption that the majority of worked items will have been trimmed to length with an edged tool (such as a flint adze or axe), the distribution of the presence of surviving tool marks and tool facets can be considered as a proxy indicator of condition (Figure 22.12). Survival of tool faceting is much lower than would normally be expected and is thought to be a result of the extreme age of the material. The majority of the ends of items, where tool faceting is most likely to be present, are degraded and can be seen to 'feather' away.

The long history of excavation at the site provides a rare opportunity to view the effects of intrusive trenching on the burial environment, within waterlogged deposits. Excavations during the current campaign revealed several areas either adjacent to or immediately beneath previous trenches.

The greatest time gap between exposures related to the excavation of the baulk between Clark's cutting I and cutting II within Clark's Area (1948 to 2015: 67 years). Surprisingly, despite lying beneath an unfinished trench and between two previous trenches, the material seen in the baulk was perhaps the best-preserved wood encountered during the current campaign. Wood directly beneath backfill or in contact with it to either side did not appear to have suffered any notable effect from the previous trenching. The animal bone and antler was also in good condition and it has been suggested that this may have been due to less acidic ground conditions, $\mathrm{pH}$ levels perhaps being stabilised to some extent by alkaline marl mixed into Clark's backfill. However, although this may account for the relatively good condition of the bone and antler, $\mathrm{pH}$ levels have been shown to have little effect on the stability of the wood. It must therefore be surmised that the historic trenching has had little impact on the in situ wood deposits in this area.

Timbers of the western platform that had previously been exposed in the base of an unnumbered trench cut by Clark in 1951 tell a similar story. Despite bearing the physical scars from hand cleaning (the edges of the 


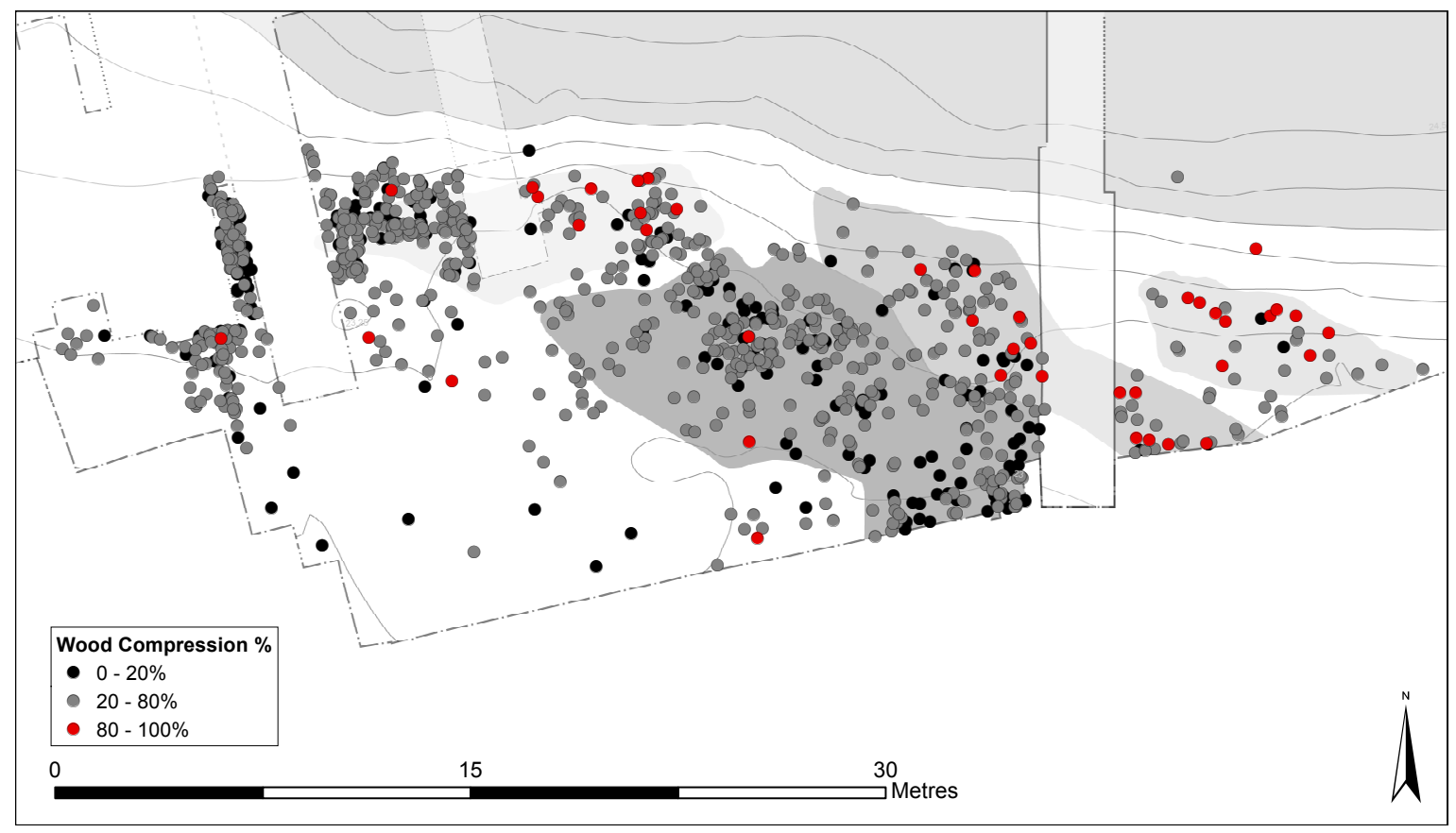

Figure 22.10: Vertical compression of wood assemblage (for full records only) (Copyright Star Carr Project, CC BY-NC 4.0).

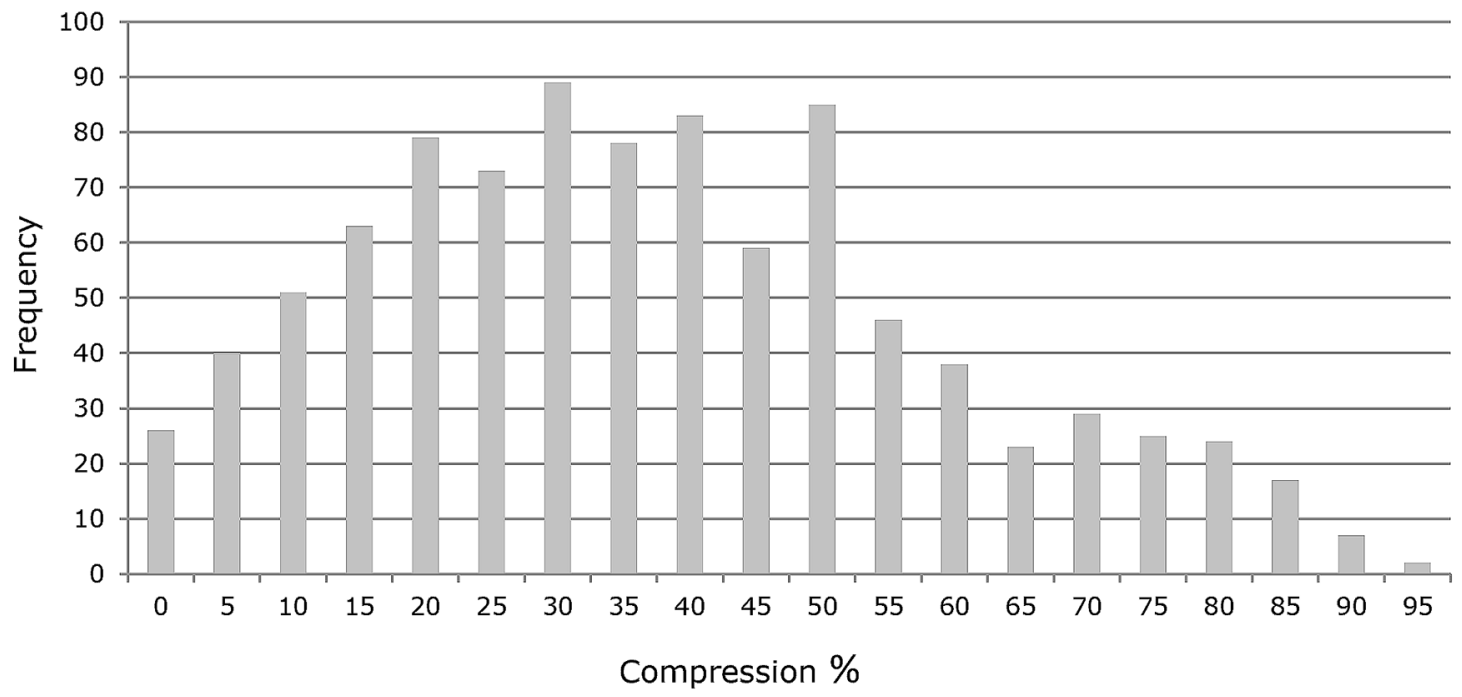

Figure 22.11: Histogram of vertical compression of wood assemblage $(\mathrm{N}=937$, full records only) (Copyright Star Carr Project, CC BY-NC 4.0). 


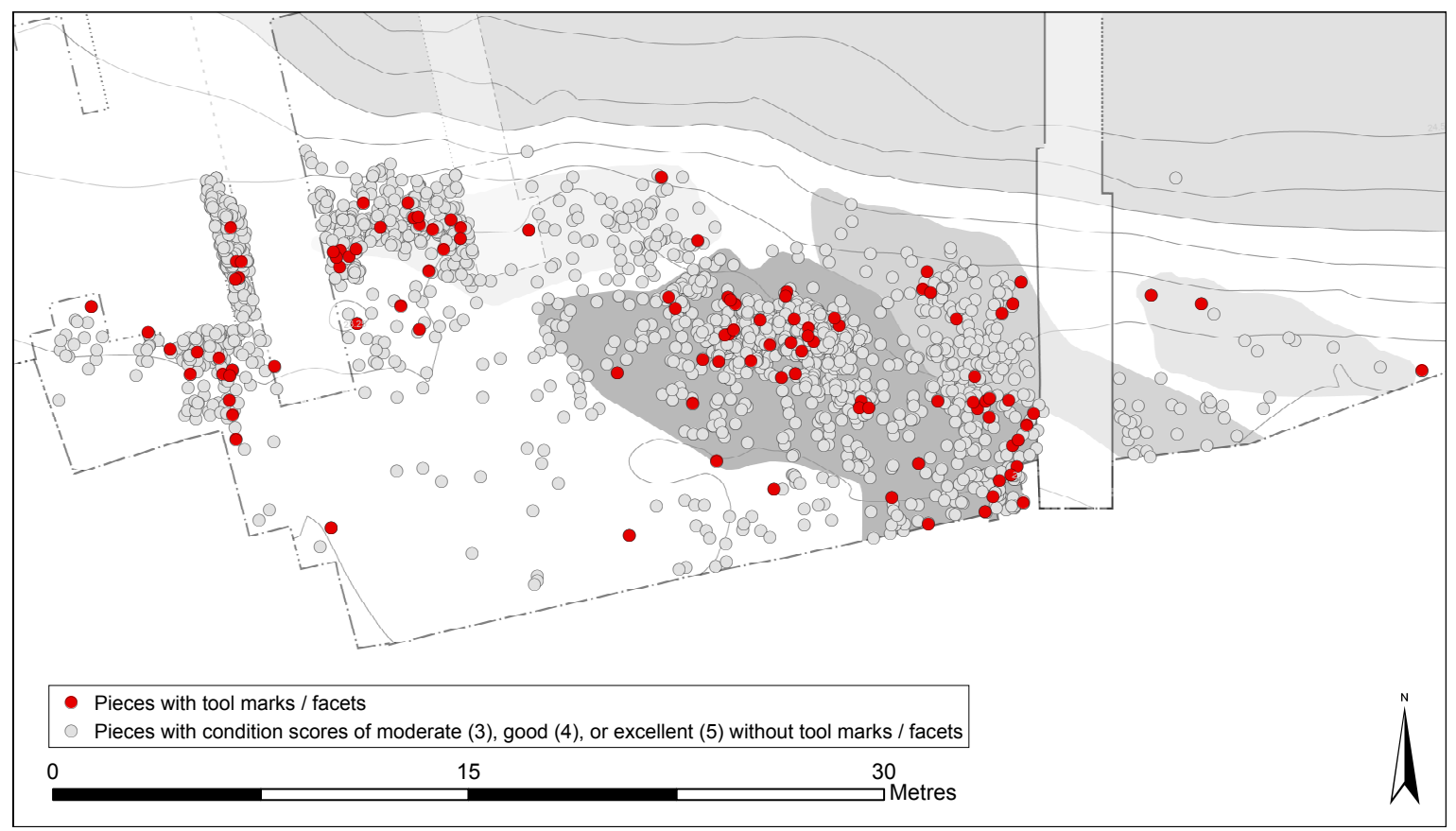

Figure 22.12: Map of tool marks and facets as proxy for information potential (Copyright Star Carr Project, CC BY-NC 4.0).

trench were clearly scored into the upper surfaces of several timbers), there was almost no apparent deterioration to the timbers.

In contrast, the timbers of the central platform, previously exposed by the 1980s excavations in trench VP85A, showed clear differential preservation when excavated in 2013 (less than 30 years later). The extent of trench VP85A was marked by orange iron salts precipitating out at the point of contact between backfill and in situ deposits. In addition, there were increased levels of surface degradation on the timbers which had previously been exposed. In sum, the detrimental effects of the previous exposure were very spatially limited, with no perceptible 'bleed in' of increased degradation away from the limits of the historic exposure.

Surprisingly, perhaps the most extreme effect of re-burial and subsequent re-excavation was seen over a single year. A few items within the detrital wood scatter were exposed during the 2013 excavations, re-buried for nine months and then re-exposed for the 2014 excavations. Many of these items suffered rapid decay, being noted to change from a good/moderate condition to a poor/very poor condition.

Although subjective, these observations show that the effects of cutting intrusive trenches into waterlogged deposits are sensitive to extremely localised conditions, and that even across a relatively small area, the effects of such trenching on the surrounding deposits are highly variable.

\section{The impact for conservation of artefacts}

The issues discussed above present a particularly challenging situation in terms of conservation of the waterlogged remains from Star Carr. Not only are we mitigating against the effect of waterlogging but also the effect of the complex chemical make-up of the burial deposits and the build-up of contaminants within the material. As such the conservation of the assemblage is unusual, with very little literature or past treatments to draw on. It should also be noted that some timbers excavated from the platform found in trench VP85A in 1985 were conserved and are currently stored at the University of York. These have not preserved well; they are crumbly with yellow powder exuding from them and produce a highly sulfurous smell.

Due to the conditions, not all the material excavated can be conserved and a strategy was drawn up as part of the English Heritage/Historic England Assessment process (Milner et al 2013a, 2014). The majority of the bone and antler has been retained for conservation but the pieces which were in the worst states of preservation, 
some categorised G-I and which had in some cases completely disintegrated, could not be saved. Given the large size of the waterlogged wood assemblage recovered from recent excavations at Star Carr and the homogenous nature of sub-groups within the assemblage, it is neither desirable nor practical to conserve or subsequently store the assemblage in its entirety. As such, a sub-sampling strategy was devised to ensure that items displaying a representative sample of the types of woodworking evidence recorded within the assemblage are conserved and subsequently retained, as well as the artefacts. Below is a summary of the conservation strategies undertaken to treat the material, based on studies done at York Archaeological Trust.

A previous study of bone from anoxic sites including Star Carr showed the presence of pyrite framboids and gypsum within the structure as well as deterioration by slow chemical hydrolysis and the action of sulfate reducing bacterial (Turner-Walker 2009). To mitigate against these effects is very challenging especially as the material would not tolerate chemical chelating treatments. There was also a very high degree of variation in the condition of the bone and antler, as outlined above, with some appearing to be in very good condition, some having undergone some degradation and softening and some having broken down entirely with no mineral content surviving.

The bone and antler material was therefore split into three categories for the purposes of the conservation treatment of good, fair and poor condition and placed into tanks. They were put through a regime of washing in tap water to try to flush out as many contaminants as possible. The washing was monitored by collecting samples and testing the iron content of the wash water. The antler frontlets were put through cascade washing to speed up the process and prevent build-up of sulfate reducing bacteria. It was not possible to be very specific about the end-point of the washing process but in this case the washing was deemed complete after approximately three months. At this point the material which was decalcified was put through a pre-treatment of glycerol to act as a protector and consolidant during drying. More robust material was dried using controlled air drying with consolidation undertaken where necessary. Once dry, the bone and antler went through further surface cleaning and consolidation where necessary, using appropriate conservation grade materials.

The wood from the site has gone through significant deterioration, both by compression and by breakdown of both lignin and cellulose and by the introduction of contaminants which lead to further attack once the material has been excavated. The conservation process, as with the bone and antler, therefore has to mitigate against the effect of compression and waterlogging, but also against the build-up of contaminants such as sulfur and iron which lead to acid attack.

As such, the initial stages of the conservation process aimed to remove as much sulfur and iron as possible using a combination of washing and chelating treatments. However, it will not have been possible to remove all such contaminants. Once the washing stage was complete, the wood was put through a standard conservation treatment using Polyethylene Glycol (PEG) and freeze-drying, and with further surface work being done, post-drying where necessary to remove excess PEG and to join fragments were necessary.

After drying and surface treatments the material is stable but the storage environment will be an important factor in its future stability. High humidity and oxygen levels in storage could lead to the oxidation and acid attack within the material. The storage environment should therefore look to provide a relative humidity which is fairly dry (between about 30-40\% relative humidity) and as low in oxygen levels as possible. However, despite both conservation intervention and provision of beneficial storage conditions, the material may still continue to deteriorate, given the levels of contamination and the difficulty in mitigating against this.

Because of the extreme conditions of this site and the problems with conservation, a number of artefacts have been recorded in 3D using image-based modelling and photogrammetry. The wood from the timber platforms for instance, were modelled on site (see Chapter 6), and the headdresses have been modelled using structure-from-motion. However, it was not possible to do this for all material excavated due to the development of the technology during the project and the time it takes for this to be carried out, as well as associated costs in terms of staffing. Nevertheless, this is an approach which could be adopted in the future for sites such as this which suffer from severe forms of degradation.

\section{Conclusions}

Analyses of antler, bone and wood from Star Carr show that site conditions are contributing to their rapid deterioration. Whilst the variations in the geochemistry make it difficult to say for certain whether site conditions have changed recently, comparison between material from Clark's excavations and material excavated recently, 
since 2004, suggests that far fewer bones are present in the well-preserved state first reported by Clark (1954), with the exception of Clark's area excavated in 2015. This makes it highly likely that rapid site deterioration has occurred within the last few decades. This is supported by the recent geochemical and hydrological surveys, which seem to suggest that drying out and subsequent acidification of the site occurred following the installation of field drains in 2000.

Whilst high sediment acidity has been shown to be the major cause of loss of bone at Star Carr (High et al. 2015, High et al. 2016b), it is likely that peat compression caused by drying out of the site is the major cause of deterioration in wooden artefacts. However, the two factors are clearly closely linked. Presence of sulfides was not necessarily a problem until loss of waterlogging allowed oxidation to proceed, resulting in the extreme and irreversible acidification of the deposits. Furthermore, the suggestion that groundwater may be percolating through the archaeology in areas of the site (Brown et al. 2013) means that any diagenetic processes will be accelerated as degradation products are 'washed away' (Hedges et al. 1995; Williams et al. 2006).

Our research has shown the importance of understanding the surrounding geology and hydrological features surrounding an archaeological site before any modifications to the local environment occur. Critically, the variability in both $\mathrm{pH}$ and organic preservation at Star Carr shows just how influential the underlying geology is to the chemical stability of a waterlogged site. This variability may also mean that very different management strategies may need to be considered for different parts of Star Carr or other sites similarly affected. The observed 'halo effect', where increased acidity is observed following excavation, further highlights the care that must be taken during management of the site.

Research into the effects of the site conditions on bone and wood show that material still buried at Star Carr is at risk, particularly if site conditions were to alter further (High 2014; High et al. in press). For example, a particularly dry summer may result in further reduction of the water table, resulting in increased acidity as more reactive sulfides are oxidised. This would lead to further demineralisation of bone and loss of cellulose in wood. This is clearly a concern given that less than $10 \%$ of the total area of the site has been excavated.

Analysis of organic materials carried out in recent years has indicated that although localised areas of moderate or neutral $\mathrm{pH}$ still exist, resulting in the recovery of some well-preserved artefacts, large parts of the Star Carr site are now so deteriorated that there can be little hope for the recovery of substantial archaeological data from organic artefacts. Whilst this seemingly rapid and recent deterioration of the Star Carr deposits can be viewed as a disaster for Star Carr itself, it has also given us the opportunity to study and monitor these changes. The lessons that have been learnt from the site can now be used to better protect other similar sites. 